\title{
EXPERIENCES IN CADASTRAL RESTITUTION AT A TOWN AFFECTED BY A NATURAL DISASTER. THE CASE OF VOLCAN, JUJUY PROVINCE, ARGENTINA
}

\author{
M. Gutiérrez Viñuales ${ }^{1}$, E. Puch Sleive ${ }^{2}$, S. Chalabe ${ }^{3}$ \\ ${ }^{1}$ Soluciones GeoEspaciales, Los Alisos, Jujuy, Argentina - mgutierrez@ soluciones-geoespaciales.com \\ ${ }^{2}$ Secretaría de Ordenamiento Territorial y Vivienda, Ministerio de Infraestructura y Vivienda, Provincia de Jujuy, Argentina - \\ emmy_psleive@yahoo.com.ar \\ ${ }^{3}$ Secretaría de Ordenamiento Territorial y Vivienda, Ministerio de Infraestructura y Vivienda, Provincia de Jujuy, Argentina - \\ susana.chalabe@gmail.com
}

KEY WORDS: UAVs, Cadaster, Surveying, Mapping, Planning, Landslides, Floods

\begin{abstract}
:
The use of UAVs (Unmanned Aerial Vehicles) as a data acquisition tool for cadastral surveying has been used for several years. The processing software and an adequate workflow make this set a powerful tool to obtain quality information quickly in order to take decisions.

This work shows the experience of using this tool and the results achieved in an urban area included in the Quebrada de Humahuaca (included in the list of World Heritage of Humanity by UNESCO) that was affected by a landslide and flooding in January of 2017. A precise and fast action was required to begin the reconstruction works of the houses that had to be demolished due to their high degree of affectation. In addition, a general update of the Cadastral Records of the town was required, which were analyzed individually from the information collected for the preparation of the Cadastral Map, the analysis of the previous cadastral information and a set of surveys carried out in each property. It includes an initial assessment of the problem, the work flow adopted, the results achieved, and a discussion of the problems detected in each phase of the work.
\end{abstract}

\section{BACKGROUND}

\subsection{Location}

The town of Volcán $\left(-23.917122^{\circ}\right.$; $\left.-65.463981^{\circ}\right)$ is located at the beginning of the Quebrada de Humahuaca in the Jujuy Province, Argentina. In 2003, the Quebrada de Humahuaca was included in the World Heritage Register by UNESCO in the category of Cultural Landscape ${ }^{1}$.

The Quebrada de Humahuaca is a narrow valley, of direction N$\mathrm{S}$, which develops along the Rio Grande with numerous minor tributaries with special hydrological activity during the southern summer months (November to April).

Along the Quebrada de Humahuaca, parallel to the Rio Grande, National Route $\mathrm{N}^{\circ} 9$ (RN9) is located, which connects Buenos Aires with La Quiaca $(1,967 \mathrm{~km})$, the northernmost border of the country. RN9 also connects Argentina with Bolivia and Chile. In particular, the town of Volcán is the first town in the Quebrada de Humahuaca, which must be crossed to access these two borders.

Its location in a tourist area and in the so-called "bi-oceanic corridor" that connects the Atlantic and Pacific Oceans, makes Volcán an important transit hub for both light vehicles and Cargo and Transport vehicles.

\subsection{Landslide and flood in 2017}

On January 10, 2017, extraordinary rainfall occurred in the Arroyo de Los Filtros basin, in the vicinity of Volcán.

These precipitations were equivalent to $50 \%$ of the annual average of precipitations and they were triggered in a lapse of 2 hours, caused a debris flow (Hungr et al., 2001) over the trace of the RN9 and the urban layout of the town.

The following images (Figure 1) show the effect of the avalanche in the area and in the town of Volcán.

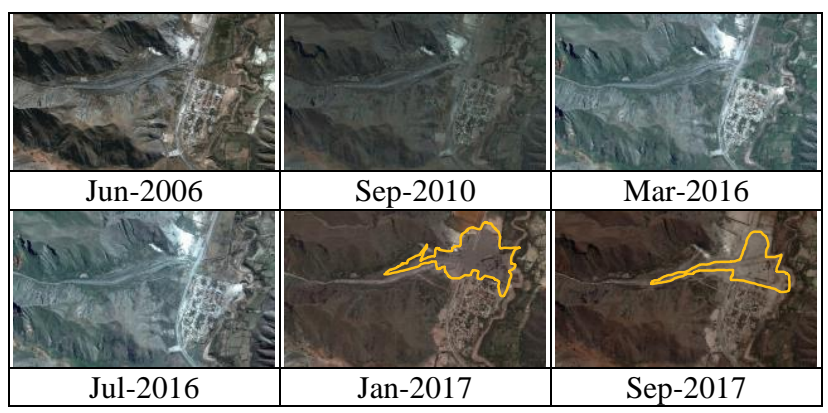

Figure 1. Evolution of Area in time

This phenomenon affected $90 \%$ of the houses of the town in varying degrees as show in Table 1.

\footnotetext{
${ }^{1}$ UNESCO, World Heritage List (https://whc.unesco.org/en/list/1116)
} 
Table 1. Property Affectation

\begin{tabular}{|l|c|}
\hline \multicolumn{1}{|c|}{ Affectation degree } & \% of properties \\
\hline Complete & $25 \%$ \\
\hline Strong & $15 \%$ \\
\hline Moderate & $50 \%$ \\
\hline Low or Null & $10 \%$ \\
\hline
\end{tabular}

\subsection{Existent cadastral information}

The assistance to the affected neighbours and the reconstruction plans of the affected dwellings, revealed an informative failure in the Cadastral and Property registers, which, although it was not an impediment to provide the necessary assistance, indicated that it should be carried out a Cadastral and Property regularization to clean up existing records.

For this reason, the Property Management of the Province of Jujuy requested the execution of a Cadastral Map that would reflect the "existing facts" and allow that regularization. Soluciones GeoEspaciales was awarded to perform this task.

\section{OBJECTIVES AND SCOPE OF WORK}

\subsection{General objectives}

The aim is to obtain updated information on the urban properties of the town of Volcán, identifying, from a photogrammetric survey and a mosaic of rectified images, the "existing facts" and plotting the properties according to this observation, to update the Digital Cadastre.

\subsection{Specific objectives}

Identify the deviations between the real occupation of the territory and the formal information of Cadastre and Property Registers.

Regularize the property information of each parcel of land from the town from updated Cadastral information and a set of surveys conducted to know the type of construction and the type of use of the property.

\section{METODOLOGY}

\subsection{Delimitation of the area under study}

The area under study for the Cadastral Registry is show in Figure 2. As natural limits, the Gral. San Martín Avenue was taken to the North, the Rio Grande to the East, the RN9 to the South and the RN9 to the West.

In this area, significant vertical elements such as trees, buildings in height and communications antennas were surveyed and located in order to use this information in the planning of flights.

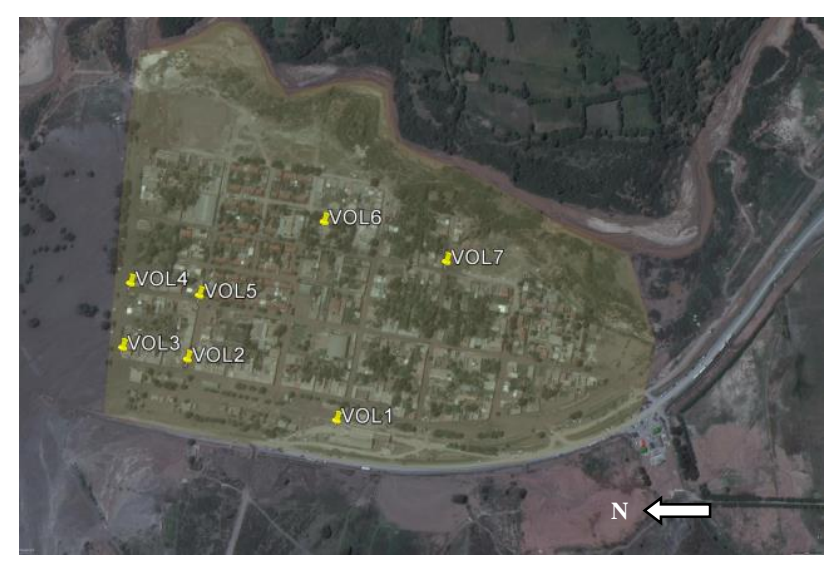

Figure 2. Area under study and GCP locations (C) 2018 DigitalGlobe (Google Earth)

\subsection{Ground Control Points (GCPs)}

Ground Control Points (GCPs) were placed in different positions distributed in the urban layout (see Figure 2), which were subsequently used in the photogrammetric process and additionally some of them served as scale controls of the threedimensional surface model (DSM).

In some cases, these marks were placed in easily identifiable unalterable points (Manyoky et al. 2011), in order to avoid the placing of marks in a possible fast campaign.

GCPs were geolocated in the POSGAR 94 Argentine Geodetic Positions System from the reference point of a nearby point ${ }^{2}$ $(7.67 \mathrm{~km})$ of the Network (M. Rijsdijk et al. 2013).

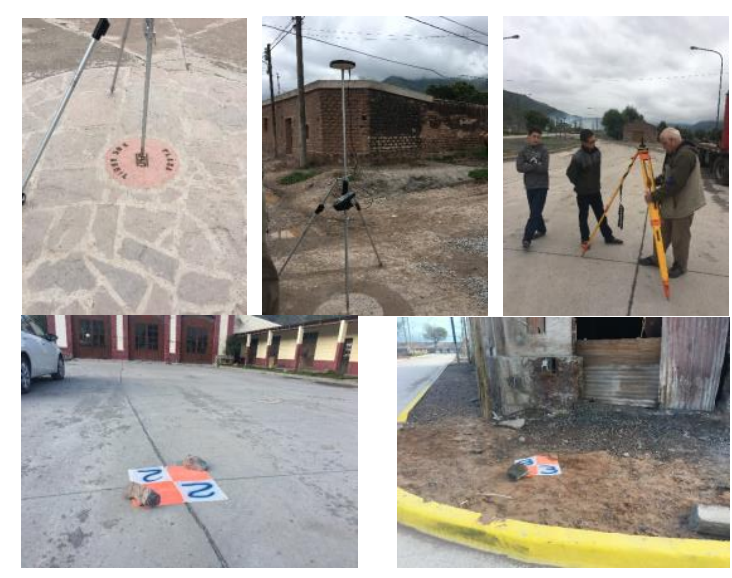

Figure 3. GCPs, Measurement and mark

\subsection{UAV Selection}

For this type of work, we have used a UAV DJI Phantom 4 Pro + , which was used during this survey.

The relevant photogrammetric features of the camera that equips this UAV are:

- Sensor:

2 JUJUY: GPS 29 (Tumbaya, Jujuy). Geodesic Coordinates (-23 50' 56.6388"; -65² 27' 53.2233"; altitude: 2,135.520) 


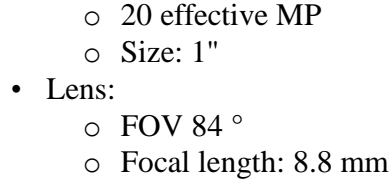

\subsection{Flight Plan, planning and considerations}

Flight Altitude: A Flight Plan was created 60 meters high from each Takeoff Base, in order to avoid obstacles, mostly trees. Special consideration was given to a communications antenna of $120 \mathrm{~m}$ in height and its fastening system (W. Volkmann et al. 2014).

Given that there are no aerodromes or commercial flight routes in the area, there were only general considerations for the flight.

Climatic and atmospheric aspects: Given the characteristics of the area, the best time to develop flights is during the first hours of the morning, since strong winds starts at noon, which prevents stable flights.

Another aspect is due that the height of the town is around 2,100 m, so, low-altitude clouds are frequently located which prevent the correct acquisition of images.

For this reason, the execution of flights in accordance with the Plan was carried out at an appropriate time to ensure its efficiency.

Layout: The general layout of the Flight Plan was made considering an approximate route in the East-West direction producing a complete sweep of the area.

The required vertical overlap based on the maximum flight speed and its height was calculated, in order to establish the interval between shots of the camera and the horizontal overlap according to the established trace.

Flight planner software was not used, due to the restrictions of the selected UAV's RC.

Take-off and Landing Bases: They were in clear areas of the town, in order to avoid interference with the normal activity of the population and avoid nearby obstacles in order to act properly in case of emergencies.

\subsection{Processing}

The selected Acquired Images $(1,254)$ were processed together with the GCP information and the Scale Factors in the Pix $4 \mathrm{D}^{3}$ software.

For which several stages were established in the Workflow, according to our internal procedures.

- Pre-Processing in-situ: Rapid Processing of data (insitu, only images and approximate verification of the calculated coordinates of the GCP), to observe coverage, general calibration of the images and global reference of georeferencing.

- Pre-Processing: Rapid processing of data to discard blured, or low-rise images (take-off or landing) or repeated images by pause in the route of the Flight Plan layout.

- Processing: Complete processing of data, including GCPs information and Scales. Obtaining Digital Surface Model (DSM) and its derivate products (Point Cloud in LAZ and XYZ format, DSM Raster in GeoTIFF format, Orthomosaic in GeoTIFF format, Level Curves to 50 $\mathrm{cm}$, Tiles and KML file to be used in Google Earth).

\section{- Post-Processing:}

- Layout of Cadastral Elements: With the information obtained from the Orthomosaic of images, the various Cadastral elements recognized in graphic form (streets, municipal lines, plots, etc.) were plotted in CAD software.

- Property Plot according to the Registered Information: As an additional layer of information, each parcel of land was drawn up according to the information available in the Records of the Property Management of the Province of Jujuy.

- Comparison of Information: By comparing the information provided by both sources (aerial survey and registered information from archives), the various irregularities found could be determined.

- Generation of Recommendations for the Property Management: Inconsistencies were tabulated and for each of parcel of land the recommendations were suggested to clean up the Public Registry of Property and the Digital Cadastral Information.

\section{RESULTS}

Figures 4, 5 and 6 shows the Cadastral Map perform from the Orthomosaic plotted using "existing facts" and other Cadastral elements.

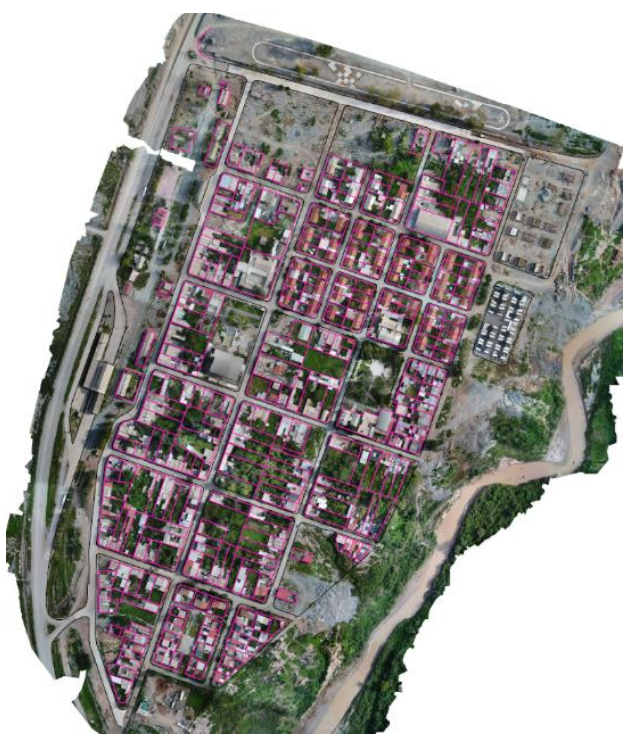

Figure 4. Cadastral Map

\footnotetext{
${ }^{3}$ Pix4Dmapper ver. 4.2 .17 (pix4d.com)
} 


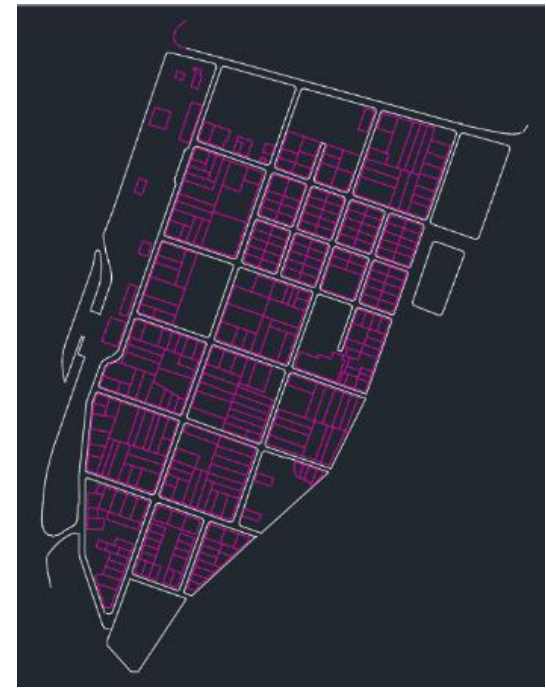

Figure 5. Cadastral Map

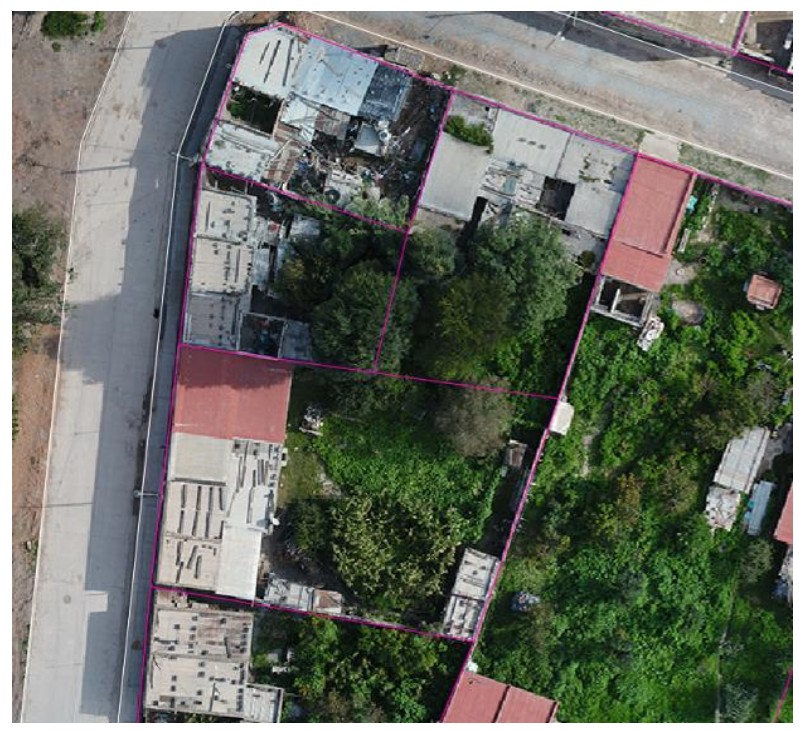

Figure 6. Detail of Cadastral Map

Figure 7 shows a Public Use Area (in this case a drainage area) occupied by constructions which should be corrected or removed.

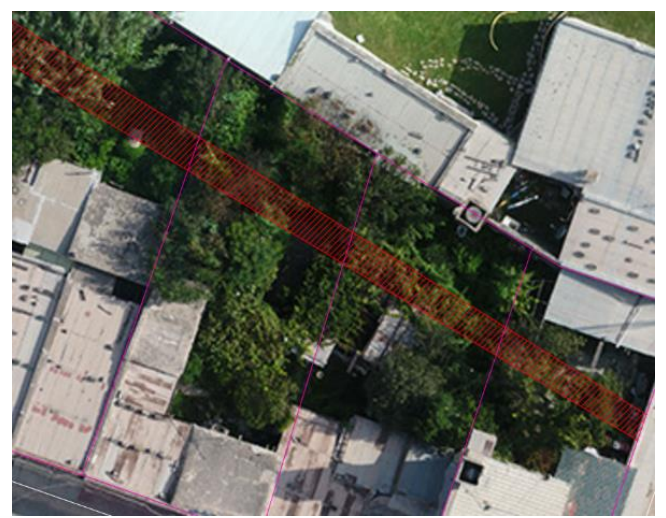

Figure 7. Hatched Area is a Drainage Area badly used by privates
The information obtained made it possible to establish all the recommendations for the new wording of the legal titles of the properties, as well as additional information on the occupation of each of the parcel of land, determining the areas occupied.

The surveys made to each owner, provided information on the type of construction, which was contrasted with the information obtained from the aerial survey.

\section{CONCLUSIONS AND RECOMMENDATIONS}

\subsection{Conclusions}

The use of UAVs has proven to offer a rapid response to solve cadastral restitution problems with a significantly acceptable accuracy.

In some cases, in which the cadastral boundaries of the parcel of land were hidden by the foliage of trees or other obstacles, it was not difficult to make assumptions that were verified in the field. Perhaps the use of a Lidar system could have been more beneficial but at a significantly higher cost.

\subsection{Recommendations}

The use of GCPs with a precise geolocation, makes possible the appropriate georeferencing and the precise adjustment of the scale of the model, which is key mark at the time of cadastral boundary delineation.

The use of a Flight Plan Software should be recommendable in order to avoid shadow areas or underlapping images. However, it is possible to carry out an adequate survey by manually establishing the criteria for a detailed Flight Plan.

Sometimes when the sensors of "obstacle avoid" system of the UAV face the sun rise above mountains, the UAV System interpret this like an obstacle, so if your knowledge of the area is good you should turn off this characteristic of the UAV.

\section{ACKNOWLEDGEMENTS}

This work was supported by "Habitat" Program from Argentina Government.

We are grateful to Eng. Humberto García and Arch. Eduardo Raúl Cazón from the Secretary of Territorial Planning and Housing from Jujuy Government.

\section{REFERENCES}

Hungr, O., Evans, S. G., Bovis, M. J., Hutchinson, J. N., 2001. A Review of Classification of Landslides of the Flow Type. Environmental \& Engineering Geoscience, Vol VII, No. 3, August 2001, pp. 221-238.

Manyoky, M., Theiler, P., Steudler, D., Eisenbeiss, H., 2011. Unmanned Aerial Vehicle in Cadastral Applications. Int. Arch. Photogramm. Remote Sens. Spatial Inf. Sci., XXXVIII-1/C22.

Rijsdijk, M., van Hinsbergh, W. H. M., Witteveen, W., ten Buuren, G. H. M., Schakelaar, G. A., Poppinga, G., van Persie, M., Ladiges, R., 2013. Unmanned Aerial Systems in the process 
of Juridical Verification of Cadastral Border. Int. Arch. Photogramm. Remote Sens. Spatial Inf. Sci., XL-1/W2.

Volkmann, W., Barnes, G., 2014. Virtual Surveying: Mapping and Modelling Cadastral Boundaries using Unmanned Aerial Systems (UAS). FIG Congress. Kuala Lumpur, Malaysia. 